\title{
Técnicas de Imobilização de Enzimas
}

\section{Kátia F. Fernandes, Claudinei S. Lima \& Flavio M. Lopes}

A imobilização de enzimas constitui uma das áreas da tecnologia enzimática que reúne um conjunto de técnicas através das quais esses catalisadores podem ser utilizados repetida e continuamente. O principal objetivo de se imobilizar enzimas é obter maiores vantagens no uso de enzimas em contraposição às desvantagens de alto custo e baixa estabilidade das preparações. Vários métodos de imobilização são conhecidos, e neste trabalho, alguns métodos clássicos são descritos e analisados.

Palavras-chave: enzimas, imobilização de enzimas, estabilidade enzimática.

Enzyme immobilization is a field of the enzymatic technology that utilizes techniques which permit enzymes to be repeatedly and continuously used. The principal interest in enzyme immobilization is to increase the advantages inherent in the use of these catalysts while decreasing the disadvantage of high cost and low stability. There are several methods used for enzyme immobilization and those more widely applied are described.

Keywords: enzymes, enzyme immobilization, enzyme stability. 


\section{Introdução}

A história de enzimologia, a ciência que estuda as enzimas, se confunda com a historia da bioquímica. Ambas tiveram seu início no século dezenove, com as investigações pioneiras sobre os processos de fermentação e digestão. A primeira Teoria Geral de Catálise Química foi postulada pelo químico Jacob J. Berzelius, em 1835, partindo da observação de que extratos de malte, chamados na época de "diastase" e que hoje se sabe contém uma mistura de amilases, catalisava a hidrólise de amido mais eficientemente do que ácido sulfurico ${ }^{1}$.

Quase dois séculos depois, a química continua a ser o sustentáculo para a elucidação dos mecanismos envolvidos na catálise enzimática. Por outro lado, a complexidade e grande número de reações ocorrendo simultaneamente nos sistemas vivos fazem da bioquímica um instrumento essencial para a compreensão das implicações biológicas dessas reações. A expansão do conhecimento e aplicações desse tipo de catálise nos dias atuais, com todas as vantagens que lhe são inerentes, tem convocado a participação cada vez mais efetiva daqueles que detêm o conhecimento das ciências químicas e bioquímicas, para solução de alguns problemas.

Por definição, enzimas são proteínas que tem, por característica funcional, a capacidade de catalisar reações. Estes catalisadores biológicos que apresentam uma alta especificidade pela reação que catalisam. Tal característica, aliada ao fato de que enzimas operam em condições de reação amenas, tais como pH neutro, pressão atmosférica e temperaturas próximas à do ambiente, desde longa data atraíram a atenção de muitos pesquisadores e industriais para o desenvolvimento de processos utilizando esses catalisadores ${ }^{2}$. No entanto, um dos entraves para o seu uso disseminado reside no custo de obtenção e purificação, assim como na baixa estabilidade das enzimas em solução, o que encarece 0 processo e, portanto, o produto final. Recentemente, a busca por tecnologias utilizando enzimas vem recebendo novo impulso, no intuito de atender às normas ISO 9000 e 14000, que estabelecem padrões de qualidade para produtos e dão ênfase ao menor consumo energético e baixo impacto ambiental dos processos ${ }^{2}$.

Neste contexto, uma das técnicas poderosas, que vêm sendo empregadas no sentido de explorar as vantagens da catálise enzimática e de minimizar suas desvantagens, é a imobilização de enzimas.

Uma das definições mais abrangentes de enzimas imobilizadas é a que considera imobilizadas "enzimas que estão fisicamente confinadas, ou localizadas em certa região definida do espaço, com retenção de suas atividades catalíticas, e que podem ser usadas repetidamente e continuamente"3.

Como descrito por Kennedy e White, o primeiro relato sobre a imobilização de enzimas foi de Nelson e Griffin que, em 1916, verificaram que invertase adsorvida em carvão ativado mantinha sua atividade e não era retirada com as lavagens. Desde esta época, vários métodos de imobilização foram desenvolvidos. É preciso ter em mente o sistema onde a enzima imobilizada será utilizada no momento da escolha do método de imobilização, uma vez que cada método traz em si limitações que precisam ser consideradas. A ligação de enzimas a suportes insolúveis é o método mais antigo e mais utilizado para imobilização ${ }^{4}$ e, apesar de existir atualmente uma diversidade muito grande de métodos, a presente revisão enfatizará os métodos mais clássicos.

\section{Métodos para imobilização de enzimas}

Há vários meios de se classificar os métodos utilizados para imobilizar enzimas. Kennedy \& White ${ }^{4}$ propuseram uma classificação que combina a natureza da interação responsável pela imobilização com a natureza do suporte utilizado (Figura 1). Nessa classificação, o termo enzimas solúveis designa os métodos em que a enzima permanece na mesma fase em que estão os substratos (reagentes) e os produtos da reação, enquanto o termo enzimas insolúveis designa aquelas que, após imobilização em material sólido, passam a constituir fase diferente do meio de reação, geralmente líquido.

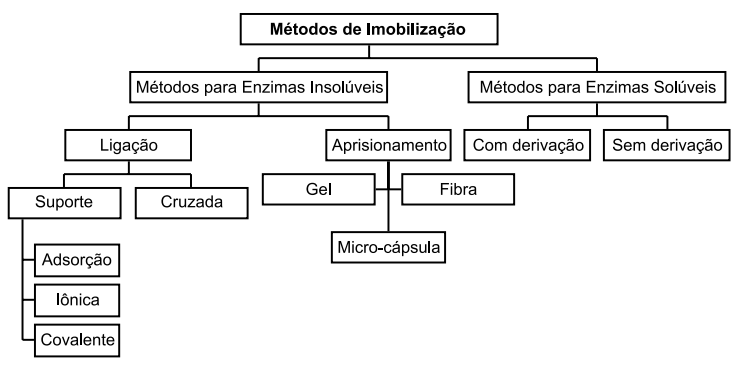

Figura 1. Classificação dos Métodos de Imobilização ${ }^{4}$. 


\section{Métodos para imobilização de enzimas solúveis}

Nestes métodos, as enzimas mantêm sua solubilidade inalterada e são separadas do restante da solução por membranas semipermeáveis, fibras porosas ou membranas de ultrafiltração. De modo geral, neste processo ocorre a contenção da enzima livre em uma câmara ou compartimento, através do qual o substrato (reagente) passa e é convertido em produto. Deste modo, é possível utilizar continuamente a enzima, na sua forma nativa, por períodos prolongados de tempo. As membranas utilizadas neste tipo de imobilização variam muito em sua composição química e tamanho de poro, podendo ser de natureza química bem simples como as de policarbonato ${ }^{5}$ (Figura 2) ou mais complexas como as de compósitos de óxido de alumínio/polietilenoimina/polianilina ${ }^{6}$.

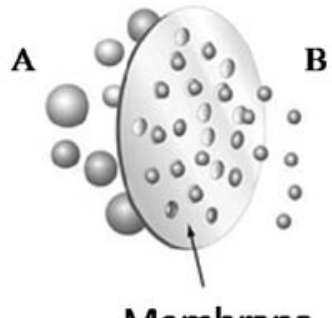

Figura 2. Membrana de Policarbonato fazendo a separação de compartimento - Compartimento A: Enzima e substrato; Compartimento B: saída do produto ${ }^{5}$.

\section{Imobilização sem modificação química da enzima}

Neste método a enzima nativa é aprisionada em uma câmara por uma membrana ou fibra, que são impermeáveis à molécula de enzima, mas são amplamente permeáveis às moléculas de substrato ou produto ${ }^{4}$. Trata-se de uma técnica extremamente simples, em que a enzima não sofre qualquer alteração em seu micro-ambiente. No entanto, há algumas restrições a sua ampla aplicação, uma vez que os produtos da reação devem ser moléculas pequenas, capazes de passar através dos poros do sistema.

\section{Imobilização com modificação química da enzima}

Este método consiste primariamente em modificar quimicamente a molécula de enzima, através da ligação de compostos de massa molar variada sem, no entanto, alterar a solubilidade da enzima nativa ou sua atividade catalítica. Deste modo, a enzima modificada adquire massa molar e diâmetro maior, permitindo a sua retenção com o uso de membranas com porosidade elevada, as quais facilitam o processo de difusão entre os ambientes, seja do substrato, seja do produto.

\section{Métodos para Preparação de Enzimas Insolúveis}

Nos métodos de enzima insolúvel, a enzima sofrerá modificação em sua solubilidade, passando a operar em fase diferente daquela do solvente, onde estarão presentes os substratos e para onde, via de regra, deverão retornar os produtos da reação. Nestes métodos, a molécula de enzima sofre tanto modificação química como no seu microambiente.

\section{Aprisionamento}

O método de aprisionamento consiste em aprisionar ou enclausurar a molécula de enzima dentro de uma matriz polimérica, de forma que seja possível a entrada do substrato e saída do produto, mas não da enzima. O método se subdivide, de acordo com o material utilizado, em aprisionamento em gel, onde são usados materiais tais como o ágar ${ }^{7}$, poliacrilamida ${ }^{8,9}$, gelatina ${ }^{10,11}$ e alginato ${ }^{8,11,12}$ (Figura 3), e aprisionamento em fibra (Figura 4) em que o acetato de celulose é um exemplo típico ${ }^{13,14}$. Uma terceira subdivisão diz respeito ao aprisionamento em nano/ microcápsulas ${ }^{15}$ (Figura 5), onde as enzimas são retidas dentro de membranas poliméricas, preparadas à partir de material semi-permeável que permitem a difusão do substrato e do produto ${ }^{16,17}$.

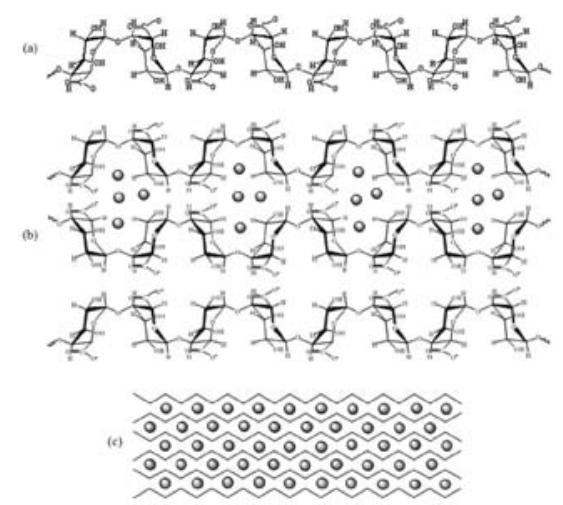

Figura 3. Formação do gel de alginato de cálcio: (a) homopolímeros de unidade de ácido gulurônico em solução; (b) ligação entre as cadeias homopoliméricas através dos íons cálcio situados entre os grupos com carga negativa aprisionando a enzima no interior da matriz; (c) formação da rede de gel com cadeias homopoliméricas com enzimas aprisionadas ${ }^{12}$. 


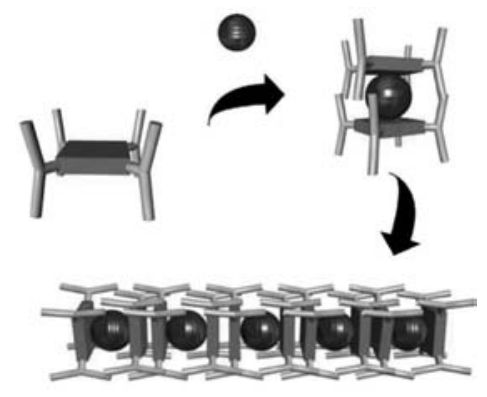

Figura 4. Aprisionamento em fibras ${ }^{14}$.

\section{Ligação ao suporte}

O método consiste na ligação da enzima a suportes insolúveis, gerando assim uma segunda fase diferente do meio reacional, onde a enzima se encontra fixada, e pode ser subclassificado de acordo com o tipo de ligação da enzima com o suporte.

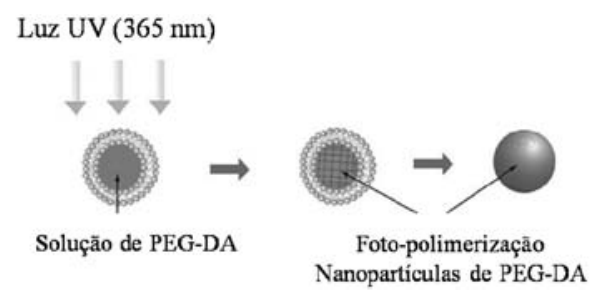

Figura 5. Preparação de nanopartículas de hidrogel. Nanopartículas contendo solução de Poli(etileno glicol) - Diacrilato (PEG-DA)

\section{Ligação ao suporte por adsorção}

Neste método de imobilização, grupos superficiais do suporte interagem com grupos de superfície da enzima, através de atrações eletrostáticas ou dipolares (forças de van der Waals) ou ainda pontes de hidrogênio ${ }^{18}$. O tipo predominante de interação depende da natureza química e propriedades superficiais do suporte e da enzima em questão ${ }^{18}$. A técnica, relativamente simples, consiste basicamente na mistura do suporte insolúvel à solução de enzima, sob condições apropriadas, seguida da separação do suporte contendo a enzima adsorvida do meio de reação.

Considerando as forças envolvidas no processo de adsorção, podemos inferir que a eficiência deste método depende de variáveis tais como $\mathrm{pH}$, força iônica do meio e a natureza do solvente empregado, bem como da relação entre a concentração da enzima e do suporte. Assim sendo, após imobilização é necessário um cuidado especial para que as condições ótimas de imobilização sejam mantidas, para que o sistema se mantenha inalterado, o que, de certa forma, limita a aplicação destes sistemas ${ }^{19}$. Apesar disto, a simplicidade e rapidez desta técnica preserva seu uso nos dias atuais com vastos exemplos de enzimas imobilizadas por adsorção ${ }^{20-24}$.

\section{Ligação Iônica}

No método de imobilização por força iônica, o suporte possui grupos funcionais ionizáveis característicos, os quais irão interagir especificamente com grupos da enzima. No processo, é possível que algum tipo de adsorção ocorra simultaneamente. Entretanto, a força da interação iônica é maior do que a de adsorção e, portanto, prevalece.

Para se obter o máximo de eficiência neste método, é necessário cuidado na escolha da solução iônica com propriedades tamponantes que será o meio para a enzima a ser ligada, de forma que seja compatível com o suporte e favoreça a substituição dos íons deste pelos grupos ionizados da enzima ${ }^{18}$.

De modo semelhante ao que ocorre com as preparações de enzimas imobilizadas por adsorção, as condições ótimas de imobilização devem ser continuamente monitoradas a fim de se preservar a integridade do sistema, em especial o pH e força iônica do meio onde a preparação será utilizada, o que também serve como limitante para a aplicação destes sistemas ${ }^{25-28}$.

Este método tem sido frequentemente utilizado na construção de biossensores em que a polianilina atua como polímero condutor depositado sobre o eletrodo (carbono vítreo, platina, ouro). A síntese de polianilina feita eletroquimicamente resulta em polímero carregado positivamente. Assim, a enzima poderá interagir ionicamente com o polímero em valores de $\mathrm{pH}$ abaixo do valor do $\mathrm{pI}^{29}$ (Figura 6).

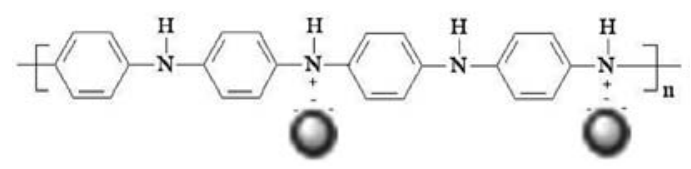

Figura 6. Imobilização por interação iônica em polianilina negativamente carregada ${ }^{29}$.

\section{Ligação covalente ao suporte}

A imobilização de enzimas através da formação de ligações covalentes entre um grupo ligante da enzima e o suporte insolúvel é um dos métodos mais largamente 
utilizados e investigados ${ }^{28,30}$. Este método emprega os mais variados tipos de ligação, sendo possível imobilizar uma enzima através de qualquer um de seus grupos superficiais reativos. Assim sendo, há uma gama imensa de reações que podem ser utilizadas para imobilização via ligação covalente ${ }^{31-39}$.

Cuidado especial deve ser tomado para que grupos importantes para o desempenho da atividade catalítica não sejam envolvidos na formação da ligação covalente entre enzima e suporte, o que teria como conseqüência uma enzima retida desprovida de atividade.

Inconvenientes desta técnica incluem as condições mais drásticas e maior número de etapas de reação e, conseqüentemente, mais tempo para sua realização. No entanto, uma vez imobilizada adequadamente, essas preparações apresentam grande estabilidade, de forma que somente alterações muito drásticas no meio serão capazes de interferir neste tipo de ligação ${ }^{4}$.

Um dos métodos mais largamente utilizados para imobilização por ligação covalente é o uso de vidro ou materiais derivados de sílica. Nestes materiais é comum o tratamento para ampliação da quantidade de grupos reativos através de silanização, seguida de introdução do braço espaçador de glutaraldeído que atuará como ponto de ligação para e enzima ${ }^{40}$ (Figura 7).

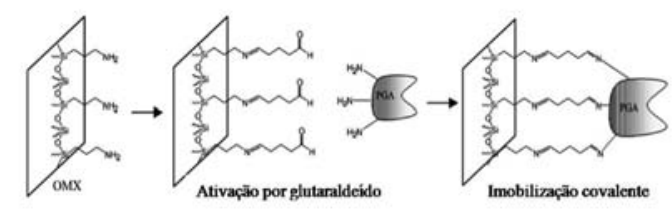

Figura 7. Imobilização covalente de Xerogel Organicamente Modificado (OMX) por multipontos ${ }^{40}$.

\section{Ligação Cruzada ou Cross-linking}

A insolubilização de enzimas por este método envolve a formação de ligação covalente entre moléculas de enzima e reagentes bifuncionais de baixa massa molar, formando agregados unidos por ligações intermoleculares. Vários meios distintos são disponíveis para o preparo de derivados insolúveis de enzimas por ligação cruzada, usando reagentes bifuncionais de baixa massa molar ${ }^{41-43}$. O sucesso da reação depende das condições experimentais e varia de acordo com a enzima e o reagente escolhido. Dentre os diversos reagentes bifuncionais existentes, destacamos o glutaraldeído como o reagente de primeira escolha, que continua a ser freqüentemente utilizado nos dias atuais em função de sua rápida reação com os grupos amino superficiais na molécula de enzima ${ }^{38,41}$. Outro reagente muito utilizado é a carbodiimida em função de sua fácil reação com grupos carboxilas ${ }^{44},{ }^{45}$. O caráter reversível ou não das reações de imobilização por ligação cruzada e, portanto, a estabilidade da ligação obtida, depende do tipo de reagente bifuncional ${ }^{31}$.

Um aspecto importante a ser ressaltado é o fato de que o método de ligação cruzada, tal qual descrito aqui, não envolve a associação da enzima com um suporte sólido. O produto da ligação de várias moléculas de enzimas através de reagentes bifuncionais é que se torna insolúvel e precipita, formando um agregado sólido cataliticamente ativo (Figura 8).

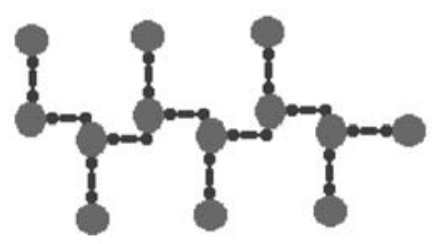

Figura 8. Imobilização por ligação cruzada "Cross-linking"

\section{A Escolha do Método de Imobilização}

A escolha do método de imobilização a ser utilizado para a imobilização de uma determinada enzima passa, necessariamente, por uma análise da aplicação a que se destina o sistema contendo a enzima imobilizada. Uma vez definida a aplicação e, portanto, as condições operacionais onde a enzima deverá atuar, podem-se então avaliar, dentre as técnicas disponíveis, aquela que melhor se adeque às necessidades exigidas. Isso posto, é importante avaliar o tempo e os custos necessários para se viabilizar o método de imobilização escolhido, uma vez que tais parâmetros irão se refletir no processo e, portanto, nos custos do produto final.

\section{Referências}

1. Voet, D.; Voet, J.G.; Biochemistry, Wiley: New York, 1995, p. 332.

2. Bom, E.; Em: Tecnologia Enzimática. Bom, E.; Pereira Jr.; Fundação Biblioteca Nacional: Rio de Janeiro, 1999, p. 17.

3. Chibata, I.; Tosa, T.; Sato, T.; Mori, T.; Em: Immobilized Enzymes Research and Development. Chibata, I.; Wiley: New York, 1978, p.1. 
4. Kennedy, J. F.; White, C. A.; Em: Handbook of Enzyme Biotechnology. Wiseman: New York, 1986, p. 147.

5. Se Yong An, S. Y.; Bui, M. N.; Nam, Y. J.; Han, K. N.; Li, C. A.; Choo, J.; Lee, E. K.; Katoh, S.; Kumada, Y.; Seong, G. H.; J. Colloid Interface Sci. 2009, 331, 98.

6. Oliveira, G.B.; Lima-Filho, J.l.; Chaves, M.E.C.; Azevedo, W.M.; Carvalho-Jr, L.B.; Reactive and Functional Polymers, 2008, 68, 27.

7. Tuoping, L.; Suhong, L; Na, W; Lirui, T. Food Chem. 2008, 109,703.

8. Lee, S. Y.; Min, B. H.; Hwang, S. H.; Koo, Y. M.; Lee, C. K.; Song, S. W.; Oh, S. Y.; Lim, S. M.; Kim, S. L.; Kim, D. I.; Biotechnol. Lett. 2001, 23, 1033.

9. Kumarl, S.; Dwevedi, A.; Kayastha, A.M.; J. Mol. Catal. B: Enzym. 2009, 58, 138.

10. Habibi-Moini, S.; D’mello, A. P.; Int. J. Pharmaceut. 2001, 215, 185.

11. Emregul, E.; Sungur, S.; Akbulut, U.; Food Chem. 2006, 97, 591.

12. Kawaguti, H. Y.; Sato, H. H.; Quim. Nova. 2008, 31, 134.

13. Kurokawa, Y.; Suzuki, K.; Tamai, Y.; Biotechnol. Bioeng. 1998, $59,651$.

14. Shirakawa, M.; Fujita, N.; Shimakoshi, H.; Hisaeda, Y.; Shinkai, S.; Tetrahedron. 2006, 62, 2016.

15. Seong, G.H.; Zhan, W; Crooks, R.M.; Anal. Chem. 2002, 74, 3372.

16. Crecchio, C.; Ruggiero, P.; Pizzigallo, M. D. R.; Biotechnol. Bioeng. 1995, 48, 585.

17. Parthasarathy, R. V.; Martin, C. R.; Nature. 1994, 369, 301.

18. Vichenewski, W.; Em: Introdução a Métodos Cromatográficos. Collins, C. H.; Braga, G. L.; Bonato, P. S.; 6.ed.; Editora da UNICAMP: Campinas, 1995, p. 59.

19. Messing, R. A.; Meth. Enzymol. 1976, 44, 148.

20. Kirkor, E. S.; Scheeline, A.; J. Phys. Chem. B 2001, 105, 6278.

21. Yang, Y.; Um, S.; J. Electroanal. Chem. 1997, 432, 71.

22. Ruzgas, T.; Gorton, L.; Emnéus, J.; Marko-Varga, G.; J. Electroanal. Chem. 1995, 391, 41.

23. Tatsuma, T.; Ariyama, K.; Oyama, N.; Anal. Chem. Acta. 1996, 318, 297.

24. Silva, L. R. D.; Gushiken, Y.; Kubota, L. T.; Coll. Surf. B: Biointerfaces 1996, 6, 309.

25. Lim, S.; Lee, K. Y.; Lee, Y. B.; Song, K. B.; Biotechnol Lett. 2001, 23, 1335.

26. Jang, K. H.; Song, K. B.; Kim, J. S.; Kim, C. H.; Chung, B. H.; Rhee, S. K.; Bioprocess. Eng. 2000, 23, 89.

27. Ivanova, V.; Dobreva, E.; Legoy, M. D.; Acta Biotechnol. 1998, $18,339$.
28. Abdel-Naby, M. A.; Ismail, A. M. S.; Ahmed, S. A.; Fattah, A. F. A.; Biores. Technol. 1998, 64, 205.

29. Chen, C.C.; Gu, Y.; Biosensor and Bioelectronics, 2008, 23, 765.

30. Kennedy, J. F.; Cabral, J. N.; Meth. Enzymol. 1987, 135, 117.

31. Zaborski, O. Em: Immobilized Enzymes; Weast, R. C.; CRC Press:Cleveland, 1974, p. 62.

32. Nahar, P.; Wali, N. M.; Gandhi, R. P.; Anal. Biochem. 2001, 294, 148.

33. Wang, P.; Daí, S.; Waezsada, S. D.; Tsao, A. Y.; Davison, B. H.; Biotechnol Bioeng. 2001, 74, 249.

34. Arica, M. Y.; Yavuz, H.; Denizli, A.; J. Appl. Polymer Sci. 2001, 81, 2702.

35. Dessouki, A. M.; Issa, G. I.; Atia, K. S.; J. Chem. Technol. Biotechno. 2001, 76, 700.

36. Balcao, V. M.; Mateo, C.; Fernandez-Lafuente, R.; Malcata, F. X.; Guisan, J. M.; Biotechnol. Prog. 2001, 17, 537.

37. Silva, K. F. F.; Tese de Doutorado, Universidade de Campinas, Brasil, 2000.

38. Wada, S.; Ichikawa, H.; Tatsumi, K.; Biotechnol. Bioeng; 1993, 42, 854.

39. Lopes, F.M.; Miidieri, S.; Fernandes, K.F.; Revista Processos Químicos, 2008, 4, 83.

40. Basso, A.; De Martin, L.; Ebert, C.; Gardossi, L.; Linda, P.; Sibilla, F.; Tetrahedron Let. 2003, 44, 5889.

41. Tyagi, R.; Gupta, M. N.; Biochemistry-Moscow; 1998, 63, 334.

42. Yang, Z.; Williams, D.; Russell, A.; Biotechnol. Bioeng. 1995, 45, 10.

43. Billiar, K.; Murray, J.; Laude, D.; Abraham, G.; Bachrach, N.; J Biomed. Mat. Res. 2001, 56, 101.

44. Dijkstra, P. J.; Zeeman, R.; Feijen, J.; Macromolec. Symp. 2001, 172, 11.

45. Palmisano, F.; Quinto, M.; Rizzi, R.; Zambonin; Analyst 2001, 126, 866.

\section{Kátia F. Fernandes ${ }^{1}$, Claudinei S. Lima $^{2,3}$ \& Flavio M. Lopes ${ }^{1,2,3 *}$.}

${ }^{1}$ Universidade Federal de Goiás, Cx. Postal 131, 74001-970 Goiânia, GO. ${ }^{2}$ Universidade Estadual de Goiás - Br 153 n 3.105 - Fazenda Barreiro do Meio - Caixa Postal:459, Anápolis, GO.

${ }^{3}$ Faculdade Anhanguera de Anápolis, Anhanguera Educacional S.A. Av. Universitária, 683, Centro CEP: 75080-150 Anápolis, GO.

*e-mail: flaviomarx@hotmail.com 